\title{
The Use of Standardized Brazilian Green Propolis Extract (EPP-AF) as an Adjunct Treatment for Hospitalized COVID-19 Patients (BeeCovid2): A Structured Summary of a Study Protocol for a Randomized Controlled Trial
}

Marcelo Augusto Duarte Silveira ( $\square$ marceloadsilveira@gmail.com )

Hospital Sao Rafael https://orcid.org/0000-0002-6808-0540

Sergio Pinto de Souza

Hospital Sao Rafael

Erica Batista dos Santos Galvão

Hospital Sao Rafael

Maurício Brito Teixeira

Hospital Sao Rafael

Marcel Miranda Dantas Gomes

Hospital Sao Rafael

Lucas Petri Damiani

HCor: Hospital do Coracao

Bruno Andrade Bahiense

Hospital Sao Rafael

Julia Barros Cabral

Hospital Sao Rafael

Cicero Wandson Luiz Macedo De Oliveira

Hospital Sao Rafael

Talita Rocha Mascarenhas

Hospital Sao Rafael

Priscila Carvalho Guedes Pinheiro

Hospital Sao Rafael

Milena Souza Alves

Hospital Sao Rafael

Rodrigo Morel Vieira de Melo

Hospital Sao Rafael

Andresa Aparecida Berretta

Apis Flora 
Flávia Mendes Leite

Hospital Sao Rafael

Carolina Kymie Vasques Nonaka

Hospital Sao Rafael

Bruno Solano de Freitas Souza

Hospital Sao Rafael

Ana Verena Almeida Mendes

Hospital Sao Rafael

Suzete Farias da Guarda

Hospital Sao Rafael

Rogério da Hora Passos

Hospital Sao Rafael

\section{Study protocol}

Keywords: COVID-19, Randomized controlled trial, Protocol, Propolis, Anti-inflammatory agents, Immunoregulation, ACE2, PAK1 blocker, TMPRSS2.

Posted Date: June 25th, 2021

DOl: https://doi.org/10.21203/rs.3.rs-617827/v1

License: (c) (i) This work is licensed under a Creative Commons Attribution 4.0 International License. Read Full License

Version of Record: A version of this preprint was published at Trials on April 4th, 2022. See the published version at https://doi.org/10.1186/s13063-022-06176-1. 


\section{Abstract \\ Background}

The 2019 coronavirus disease (COVID-19) pandemic continues to spread and affects large numbers of people with unprecedented impacts. To date, there is no consensus on a specific treatment. Experimental evidence has already been obtained for use of the standardized extract of Brazilian green propolis (EPPAF) against viral targets, and clinical rationality has been demonstrated for testing this extract as an adjunct to treatment in patients affected by COVID-19. The BeeCovid2 study is once again assessing EPP-AF in hospitalized patients with coronavirus infection.

\section{Methods}

BeeCovid2 is a randomized, double-blinded, placebo-controlled clinical study being conducted in Brazil to provide further evidence on the effectiveness of standardized green propolis extract as an adjunctive treatment for adults hospitalized with COVID-19. Adults hospitalized with COVID-19 with respiratory symptoms for less than 14 days who are not on invasive oxygen therapy are eligible. Enrolled patients are randomized at a 1:1 ratio to receive placebo or standardized propolis extract ( $900 \mathrm{mg} /$ day) for 10 days. The study treatments are administered in a double-blinded manner, and patients are followed for 28 days. The primary outcome is the length of hospital stay. Secondary outcomes include the need for mechanical ventilation, the rate of acute kidney injury, the need for renal replacement therapy, the requirement for vasoactive drugs, the use of an intra-aortic balloon pump (IABP), and the use of extracorporeal membrane oxygenation (ECMO).

\section{Discussion}

This trial is very useful and will provide more data on the effectiveness of using the standardized Brazilian green propolis extract as an adjunctive treatment in association with standard care in adults hospitalized with moderate to severe acute COVID-19.

\section{Trial registration:}

ClinicalTrials.gov NCT04800224. Registered on March 16, 2021.

\section{Background}

The COVID-19 pandemic is of great concern because of its unprecedented impact on human health [1]. The disease, after the replication phase, promotes inflammatory and immunological events, and even with advances in knowledge of its pathophysiology, we still do not have a specific treatment [2]. 
Coronavirus infection therefore presents immunological and inflammatory challenges for clinical practice. Experimental and clinical evidence points to novel variants of the virus with greater infectivity and enhanced promotion of immune-inflammatory processes [3]. Further understanding and the search for strategies that concurrently impact both of these mechanisms can bring about a reasonable solution for patients affected by the disease, mainly because the response to these events is heterogeneous, and modulation of this response may be the best strategy $[1,4]$.

Propolis is a natural resin with considerable evidence of antioxidant, antiviral, antiproteinuric, immunoregulatory and anti-inflammatory activities, and experimental data point to its potential actions against viral targets $[1,5-7]$.

\section{Propolis: Experimental Evidence Against Viral Targets}

The coronavirus uses several mechanisms in the processes of activation, cell invasion, replication and the triggering of inflammatory mechanisms [1].

The entry of SARS-CoV-2 into target cells requires binding of the spike protein to angiotensin-converting enzyme 2 (ACE2) [8]. The spike protein is first activated by the membrane protease human transmembrane protease 2 (TMPRSS2) [1, 8]. After switching on, several signals are triggered, allowing for viral endocytosis and activation of the PAK1 inflammatory pathway, which reduces the adaptive immune response and the production of antibodies against the virus [9]. The PAK1 pathway also promotes the activity of $\mathrm{C}-\mathrm{C}$ pathway motif chemokine ligand 2 (CCL2), which is associated with stimulating pulmonary fibrosis [1]. Viral infection induces activation of the nuclear transition factor (NF$K B)$, generating local production of proinflammatory cytokines and activation of the inflammasome NLRP3 pathway with production of interleukin-1 $\beta$ (IL-1 $\beta$ ) [1]. Further, macrophage and monocyte activation occurs, as well as production of additional cytokines, including TNF and IL-6. Compounds derived from green propolis negatively regulate the expression of TMPRSS2 and the anchoring of ACE2, which limits entry of the virus $[10,11]$. Additionally, these compounds promote the immunomodulation of NF-KB, the NLRP3 inflammasome and monocytes/macrophages, reducing the overproduction of proinflammatory cytokines $[1,6,7]$. Experimental evidence also points to propolis substances capable of reducing activation of the PAK1 pathway, an important target used by the virus to shield itself from adaptive immunity [12].

\section{Clinical evidence from the use of standardized green propolis extract for COVID-19}

Clinical evidence has begun to emerge that has increased understanding of the therapeutic possibilities of using propolis to combat the coronavirus.

The first clinical study using propolis in patients with COVID-19 worldwide was recently published in the scientific literature [2]. It was randomized, controlled and open and was conducted at Hospital São Rafael in Salvador, Bahia, Brazil. After approval by the National Research Ethics Committee in Brazil, it was 
registered on the clinicaltrials.gov platform (NCT04480593). Standardized Brazilian green propolis extract (EPP-AF) was used at two different doses (low and high doses). This study included 124 patients who were divided into three groups: the control group $(n=42)$, the EPP-AF group receiving $400 \mathrm{mg} /$ day $(\mathrm{n}$ $=40)$, and the EPP-AF group receiving $800 \mathrm{mg} /$ day $(n=42)[2]$.

All patients received standard treatment that included the use of corticosteroids, antibiotics, antivirals, oxygen therapy or any necessary support (e.g., extracorporeal membrane oxygenation [ECMO], intra-aortic balloon pump [IABP], dialysis). The study protocol did not interfere with decisions about supportive treatment. The primary outcome assessed was the time to disease recovery, inferred by length of hospital stay after randomization. The length of hospital stay postintervention was shorter in both propolis groups than in the control group: in the low dose group, the median stay was 7 days versus 12 days $(95 \%$ confidence interval $[\mathrm{Cl}]-6.23$ to $-0.07 ; \mathrm{p}=0.049$ ); and in the high dose group, the median stay was 6 days versus 12 days $(95 \% \mathrm{Cl}-7.00$ to $-1.09 ; p=0.009)$ [two]. The patients who received EPP-AF at the highest dose had a significantly lower rate of acute kidney injury than those in the control group $(23.8 \%$ vs. $4.8 \%, p=0.048)$ [2]. The study had limitations: it was an open, single-center study and did not include a placebo group. The use of propolis at the studied doses was safe and beneficial, and the baseline characteristics of the participants were similar with regard to comorbidities, duration of illness, degree of lung involvement (as assessed by tomography), and oxygen therapy.

\section{Methods}

\section{Design and oversight}

BeeCovid2 is a randomized, double-blinded, placebo-controlled clinical trial being conducted at Hospital São Rafael, a tertiary hospital in Salvador, Bahia, northeastern Brazil. This study began on April 14, 2021, with the aim of including other centers.

The protocol was approved by the Local Ethics Committee (Registration number 43265321.9.0000.0048) on February 25, 2021, and the trial was registered on March 16, 2021, on ClinicalTrials.gov (NCT04800224). The study is being conducted in accordance with the principles of the Declaration of Helsinki and the guidelines of Good Clinical Practice of the International Harmonization Conference. All participating patients and/or legal representatives are informed about the objectives and risks of participation before signing the informed consent form. The informed consent is electronically signed, stored on the Research Electronic Data Capture (RedCap) platform and automatically made available to participants via download. Electronic informed consent was appreciated and approved by the local ethics committee, and it offers more security to the research team. Table 1.

Table 1. Participant timeline 


\begin{tabular}{|c|c|c|c|c|c|c|c|c|c|}
\hline \multirow[b]{3}{*}{ Timepoint } & \multicolumn{9}{|c|}{ Study period } \\
\hline & \multicolumn{4}{|c|}{$\begin{array}{l}\text { Enrolment / } \\
\text { Allocation }\end{array}$} & \multicolumn{4}{|c|}{ Post-Allocation } & \multirow{2}{*}{$\begin{array}{l}\text { Close- } \\
\text { out } \\
\text { Augus } \\
2021\end{array}$} \\
\hline & $\begin{array}{l}\text { April } \\
2021\end{array}$ & $\begin{array}{l}\text { May } \\
2021\end{array}$ & $\begin{array}{l}\text { June } \\
2021\end{array}$ & $\begin{array}{l}\text { July } \\
2021\end{array}$ & $\begin{array}{l}\text { April } \\
2021\end{array}$ & $\begin{array}{l}\text { May } \\
2021\end{array}$ & $\begin{array}{l}\text { June } \\
2021\end{array}$ & $\begin{array}{l}\text { July } \\
2021\end{array}$ & \\
\hline \multirow{4}{*}{$\begin{array}{l}\text { Enrolment: } \\
\text { Eligibility screen } \\
\text { Informed consent } \\
\text { Allocation }\end{array}$} & & & & & & & & & \\
\hline & $\mathrm{x}$ & $\mathrm{x}$ & $\mathrm{x}$ & $\mathrm{x}$ & & & & & \\
\hline & $\mathrm{x}$ & $\mathrm{x}$ & $\mathrm{x}$ & $\mathrm{x}$ & & & & & \\
\hline & $\mathrm{x}$ & $\mathrm{x}$ & $\mathrm{x}$ & $\mathrm{x}$ & & & & & \\
\hline \multirow{3}{*}{$\begin{array}{l}\text { Interventions: } \\
\text { A: Propolis (EPP-AF) + } \\
\text { standard care } \\
\text { B: Placebo + standard } \\
\text { care }\end{array}$} & & & & & & & & & \\
\hline & & & & & 4 & & & $\rightarrow$ & \\
\hline & & & & & & & & $\rightarrow$ & \\
\hline \multirow{4}{*}{$\begin{array}{l}\text { Assessment: } \\
\text { Baseline Information } \\
\text { Outcomes variables } \\
\text { Adverse events } \\
\text { monitoring }\end{array}$} & & & & & & & & & \\
\hline & $x$ & $\mathrm{x}$ & $x$ & $\mathrm{x}$ & & & & & \\
\hline & & & & & & & & & $\mathrm{x}$ \\
\hline & & & & & $\mathrm{x}$ & $\mathrm{x}$ & $\mathrm{x}$ & $\mathrm{x}$ & \\
\hline
\end{tabular}

\section{Trial participants}

Hospitalized patients over 18 and under 80 years of age diagnosed with SARS-CoV-2 infection, confirmed by reverse transcriptase-polymerase chain reaction, are considered eligible if symptoms started within 14 days of the randomization date. Exclusion criteria include patients undergoing invasive oxygen therapy at the time of randomization, pregnancy or lactation, known hypersensitivity to propolis or recent use within the prior 30 days, active cancer, human immunodeficiency virus positivity, solid organ or bone marrow transplant, use of immunosuppressive drugs, bacterial or fungal infection at randomization, sepsis or septic shock, inability to administer medication orally or via a nasoenteral tube, known liver failure, advanced heart failure (New York Heart Association [NYHA] class III or IV) or end-stage kidney disease.

\section{Treatment groups and justification of dose used}

Eligible patients are randomly assigned at a 1:1 ratio to receive Propomax ${ }^{\circledR}$ capsules produced with dehydrated standardized Brazilian green propolis extract, EPP-AF®, for ten days at $900 \mathrm{mg} /$ day (three 100-mg capsules, three times per day) or placebo (three capsules, three times per day). Both groups receive the standard treatment. The standard treatment includes supplemental oxygen, noninvasive or invasive ventilation, corticosteroids, antibiotics and/or antivirals, vasopressor support, renal replacement therapy, IABP and ECMO, as needed.

The dose of standardized Brazilian green propolis extract was chosen based on studies that used similar doses without observing adverse effects $[2,5,13]$. The propolis extract being used in this study was 
prepared from a single batch to ensure for uniformity. High-performance liquid chromatography (HPLC) was performed for the batch used prior to making the capsules.

Patients are evaluated daily during hospitalization, from days 1 to 28 . Patients who are discharged before 10 days complete treatment at home and are followed up by telephone. The data for patients who cannot be reached for the 28-day follow-up are censored at hospital discharge. The standardized Brazilian green propolis extract, which is composed mainly of green propolis produced in southeastern Brazil and processed with a specific extraction and drying process, was selected for use in this study due to its batch-to-batch reproducibility $[14,15]$. The dosage of $900 \mathrm{mg} /$ day proportionally offers $47.7 \mathrm{mg}$ of total flavonoids, such as quercetin (measured according to procedures previously described by Woisky and Salatino [16]), and $121.5 \mathrm{mg}$ of total phenolics, such as gallic acid (according to Rocha et al. [17]).

\section{Blinding (masking)}

The study is double-blinded, so neither the patients, the health team involved in the patients' care, nor the principal investigator know to which group the patients are allocated.

The packaging housing the capsules contains the same labeling, is opaque and has a security system to prevent improper opening. All capsules have the same organoleptic characteristics, so there is no distinction between propolis and placebo.

Decisions about standard supportive care are made by attending physicians who are not involved in the study design or randomization process.

\section{Randomization}

The randomization is stratified based on the following clinical parameters related to the need for supplemental oxygen: no use of oxygen, nasal catheter up to $5 \mathrm{~L} / \mathrm{min}$, nasal catheter $>5 \mathrm{~L} / \mathrm{min}$ or nonrebreather mask, CPAP, or high-flow nasal cannula. Randomization is carried out from swapped blocks listed on the REDCap platform. To minimize bias, concealment of allocation and drawing is performed by a trained professional who is not connected to the study. Data analysis and statistical planning are performed by an external and impartial statistician with no patient involvement. To date, there has been no interim analysis.

\section{Outcomes}

The primary end point is the time to clinical improvement, defined as the length of hospital stay in days. The secondary outcomes include the percentage of participants who require mechanical ventilation, acute kidney injury rate, need for renal replacement therapy, requirement for vasoactive drugs, need for IABP, or requirement for ECMO. There is a program used to analyze several interleukins before and after the intervention in some of the participants. We are also assess the death rate.

Acute kidney injury is defined according to the Kidney Disease: Improving Global Outcomes (KDIGO) as stage 1 (increase in serum creatinine of $0.3 \mathrm{mg} / \mathrm{dl}$ in 48 hours or increase in baseline serum creatinine by 
1.5 to 1.9 times in 7 days), stage 2 (increase in serum creatinine by 2.9 times in seven days) or stage 3 (3fold or more increase in serum creatinine in seven days or initiation of renal replacement therapy).

Safety results include adverse events that occur during treatment, serious adverse events and premature or temporary discontinuation of treatment. Severe adverse events (pregnancy, life-threatening illness, new hospitalization, or death) are reported to the local ethics committee and the national research ethics committee.

Adverse events are classified according to the National Cancer Institute Common Terminology Criteria for Adverse Events, version 4.03

\section{Data collection and monitoring}

Randomization and data collection are carried out through the REDCap program. The program is secure and designed for data capture with intuitive interfaces.

The randomization module in REDCap allows the statistician to load a randomization table that enables him or her to draw assignments at random. The drawn assignments are designated by a trained professional who is not involved in patient care. The program allows for a secure and self-sufficient database and enables exportation of the data to statistical programs.

The data are fed and reviewed in a blinded and remote manner, ensuring accuracy and integrity according to the study's monitoring protocol and plan.

Patients are be monitored to ensure safety, which is the major premise of the entire study. Adverse events that may compromise patient safety or are considered serious or severe are reported to the local research ethics committee (within 24 hours), an independent organization, and such events could result in interruption of the study, regardless of the study results or stage.

\section{Statistical analysis}

In this section, we describe the main statistical resources for this clinical trial.

\section{Analysis of the primary outcome}

The main analysis of the study is being conducted under the intention to treat precept.

The primary outcome of the study is defined as the length of hospital stay from truncated randomization to 28 days if the patient remains hospitalized after that period. Additionally, if the patient does not survive hospitalization, we consider a length of hospital stay equal to 28 days as the primary endpoint, even if death occurs within an interval of less than 28 days after randomization. The between-group comparison is evaluated by generalized additive models assuming beta-binomial distribution, with adjustment by the stratification variable (type of oxygenation at baseline) and presented with $95 \%$ confidence intervals.

\section{Analysis of secondary and safety outcomes}


Secondary binary outcomes, such as the need for dialysis and mortality, are evaluated by logistic regression models and presented relative to chance with respective $95 \%$ confidence intervals. Continuous outcomes are described by means and standard deviations and compared by generalized regression models with distributions that best fit the data. More details are provided in the statistical analysis plan.

All secondary outcomes are adjusted by the stratification variable. Unadjusted models are subjected to sensitivity analyses.

Safety outcomes include adverse events that occur during treatment, serious adverse events, and premature or temporary discontinuation of treatment. Adverse events are classified according to the National Cancer Institute Common Terminology Criteria for Adverse Events, version 4.03.

Statistical analyses are performed using R software (R Core Team, Vienna, Austria).

\section{Sample size and power}

The average length of hospital stay in the control group in the BeeCovid study was 12.6 days with a standard deviation of 6.5 days [2]. Based on this premise, a study with 200 individuals allocated 1:1 has a power of at least $90 \%$ to identify an average effect for 3 days of hospital stay between the propolis and placebo groups.

\section{Discussion}

BeeCovid2 is a randomized, double-blinded, placebo-controlled study that assesses the effectiveness of standardized green propolis extract as an adjunct treatment in adults hospitalized with moderate to severe acute COVID-19. The first patient was enrolled on April 14, 2021, and the trial is scheduled for completion in July 2021.

The standardized extract of Brazilian green propolis has already undergone clinical trials evaluating its safety, drug interaction and effectiveness in chronic and acute diseases $[2,5,13,18]$. The standardization of the product used in this study, as well as its characterization by high-performance liquid chromatography (HPLC), guarantee uniformity and enable its use in clinical trials.

The pilot open randomized clinical trial (BeeCovid) demonstrated the safety of the two doses tested (400 $\mathrm{mg} /$ day and $800 \mathrm{mg} /$ day), as well as the benefit in anticipating clinical recovery inferred by the reduction in hospital stay [2]. The higher dose studied was also associated with a lower rate of acute kidney injury. It is known that COVID-19-associated acute kidney injury is multifactorial and is correlated with worse outcomes. Among the mechanisms are dysregulation of the immune response, cytokine storm/inflammation, endothelial lesions (formation of microthrombi) and renal tubular lesions [2]. The standardized extract of green propolis EPP-AF has already demonstrated protective efficacy in an experimental model of sepsis, with evident contributions to the protection of glomerular filtration and tubular function, reduction of cytokines and macrophage infiltration in renal tissue, immunoregulation of TLR4 and NF-KB and reduction of lung inflammation [6]. 
The increase in the number of cases, as well as the greater potential for infectivity and inflammation of the new variants, has prompted the search for tools to fight a disease without a specific treatment, and that causes immunological and inflammatory challenges [3]. Immunomodulation and the concomitant reduction in inflammation acting on viral targets may be a good strategy to study.

Several experimental studies have already demonstrated the effects of substances present in green propolis against pathways used by the coronavirus to enter cells, trigger exaggerated inflammatory mechanisms and promote immune responses with disordered orchestration [1, 7-12].

Although the existing evidence and initial clinical data support the safety of standardized green propolis extract, new evidence for efficacy is needed. BeeCovid2 has been designed to provide accurate efficacy data. The presentation and design of the study protocol, with the methodological and statistical details, are intended to enable the study to be conducted under guidelines with respect to research ethics and according to the recommendation for Clinical Interventional Trials (SPIRIT) guideline.

\section{Trial status}

The study is currently underway, with respect to the entire methodological design. The BeeCovid2 clinical trial was launched in March 2021 and began on April 14, 2021. The study started at a single center at Hospital São Rafael, Salvador, Bahia, Brazil.

The study is funded by the D'Or Institute for Education and Research. Maria Emília Pedreira Freire de Carvalho Foundation (FME), a nonprofit institution, collaborated with the study. The donation of standardized extract of Brazilian green propolis (EPP-AF) and placebo was made by Apis Flora Indl. Coml. Ltda. The completion of this clinical study is scheduled for July 30, 2021.

\section{Declarations}

The study is being conducted in accordance with the principles of the Declaration of Helsinki and the guidelines of Good Clinical Practice of the International Harmonization Conference and was approved by the Independent Ethics Committee for Analysis of Research Projects at Hospital São Rafael, Salvador, Bahia, Brazil, on February 25, 2021; Registry No. 43265321.9.0000.0048). The study was registered at ClinicalTrials.gov on March 16, 2021 (identifier NCT04800224). Informed consent is obtained from all participants or their legally authorized representatives before involvement in the study.

\section{Acknowledgments}

The authors thank the patients for their valuable contributions. The authors also thank Apis Flora Indl. Coml. Ltda. for providing the propolis and placebo, Maria Emília Pedreira Freire de Carvalho Foundation support and the staff of the D'Or Institute for Research and Education (IDOR) and Hospital São Rafael for their assistance.

\section{Disclaimer}

Page $10 / 13$ 
The content of this manuscript is the responsibility and initiative of the authors.

\section{Authors' contributions}

All authors read and approved the final manuscript. Study concept and design: MADS, RHP, SFG, AVAM, SPS, MBT, MMDG, and EBSG. Drafting of the manuscript: MADS, RHP, SFG, and LPD. Critical revision of the manuscript: Marcelo, MADS, RHP, SFG, AVAM, LPD, RMVM, and SPS.

Obtained funding: MADS, RHP, and SFG. Study supervision: All authors.

\section{Authors' information}

Not applicable

\section{Funding}

The study is funded by the D'Or Institute for Education and Research. Maria Emília Pedreira Freire de Carvalho Foundation (FME), a nonprofit institution headquartered in Salvador, Bahia, Brazil, contributed to the study. The standardized extract of Brazilian green propolis (EPP-AF) and placebo were donated by Apis Flora Indl. Coml. Ltda.

\section{Availability of data and materials}

Not applicable.

\section{Consent for publication}

Not applicable.

\section{Competing interests}

The authors declare that they have no competing interests.

\section{References}

1. Berretta AA, Silveira MAD, Cóndor Capcha JM, De Jong D. Propolis and its potential against SARS-CoV2 infection mechanisms and COVID-19 disease: Running title: Propolis against SARS-CoV-2 infection and COVID-19. Biomed Pharmacother. 2020;131:110622. https://doi:10.1016/j.biopha.2020.110622.

2. Silveira MAD, De Jong D, Berretta AA, Galvão EBS, Ribeiro JC, Cerqueira-Silva T, et.al. Efficacy of Brazilian green propolis (EPP-AF®) as an adjunct treatment for hospitalized COVID-19 patients: A randomized, controlled clinical trial. Biomed Pharmacother. 2021;138:111526.

https://doi.org/10.1016/j.biopha.2021.111526. 
3. Korber B, Fischer WM, Gnanakaran S, Yoon H, Theiler J, Abfalterer W, et.al. Tracking Changes in SARSCoV-2 Spike: Evidence that D614G Increases Infectivity of the COVID-19 Virus. Cell. 2020;182(4):812827.e19. https://doi:10.1016/j.cell.2020.06.043.

4. Ye Q, Wang B, Mao J. The pathogenesis and treatment of the 'Cytokine Storm' in COVID-19. J Infect. 2020;80(6):607-613. https://doi:10.1016/j.jinf.2020.03.037.

5. Silveira MAD, Teles F, Berretta AA, Sanches TR, Rodrigues CE, Seguro AC, Andrade L. Effects of Brazilian green propolis on proteinuria and renal function in patients with chronic kidney disease: a randomized, double-blind, placebo-controlled trial. BMC Nephrol. 2019;20(1):140.

https://doi.org/10.1186/s12882-019-1337-7.

6. Silveira MAD, Capcha JMC, Sanches TR, de Sousa Moreira R, Garnica MS, Shimizu MH, Berretta A, Teles F, Noronha IL, Andrade L. Green propolis extract attenuates acute kidney injury and lung injury in a rat model of sepsis. Sci Rep. 2021;11(1):5925. https://doi:10.1038/s41598-021-85124-6.

7. Hori JI, Zamboni DS, Carrão DB, Goldman GH, Berretta AA. The Inhibition of Inflammasome by Brazilian Propolis (EPP-AF). Evid Based Complement Alternat Med. 2013;2013:418508. https://doi:10.1155/2013/418508.

8. Hoffmann M, Kleine-Weber H, Schroeder S, Krüger N, Herrler T, Erichsen S, Schiergens TS, et.al. SARSCoV-2 Cell Entry Depends on ACE2 and TMPRSS2 and Is Blocked by a Clinically Proven Protease Inhibitor. Cell. 2020;181(2):271-280.e8. https://doi:10.1016/j.cell.2020.02.052.

9. Maruta H, He H. PAK1-blockers: Potential Therapeutics against COVID-19. Med Drug Discov. 2020;6:100039. https://doi:10.1016/j.medidd.2020.100039.

10. H.I. Güler, G. Tatar, O. Yildiz, A.O. Belduz, S. Kolayli. Investigation of potential inhibitor properties of ethanolic propolis extracts against ACE-II receptors for COVID-19 treatment by Molecular Docking Study. ScienceOpen Preprints (2020), https://DOI:10.14293/S2199-1006.1.SOR-.PP5BWN4.v1.

11. Da J, Xu M, Wang Y, Li W, Lu M, Wang Z. Kaempferol Promotes Apoptosis While Inhibiting Cell Proliferation via Androgen-Dependent Pathway and Suppressing Vasculogenic Mimicry and Invasion in Prostate Cancer. Anal Cell Pathol (Amst). 2019;2019:1907698. https://doi:10.1155/2019/1907698.

12. Xu JW, lkeda K, Kobayakawa A, et al. Downregulation of Rac1 activation by caffeic acid in aortic smooth muscle cells. Life Sci. 2005;76(24):2861-2872. https://doi:10.1016/j.Ifs.2004.11.015.

13. Cusinato DAC, Martinez EZ, Cintra MTC, Filgueira GCO, Berretta AA, Lanchote VL, Coelho EB.

Evaluation of potential herbal-drug interactions of a standardized propolis extract (EPP-AF®) using an in vivo cocktail approach. J Ethnopharmacol. 2019;245:112174. https://doi:10.1016/j.jep.2019.112174.

14. Berretta AA, Nascimento AP, Bueno PC, Vaz MM, Marchetti JM. Propolis standardized extract (EPP$A F \circledast)$, an innovative chemically and biologically reproducible pharmaceutical compound for treating 
wounds. Int J Biol Sci. 2012;8(4):512-521. https://doi:10.7150/ijbs.3641.

15. Marquiafável FS, Nascimento AP, Barud HdS, Marquele-Oliveira F, de-Freitas LAP, Bastos JK and Berretta AA. Development and characterization of a novel standardized propolis dry extract obtained by factorial design with high artepillin C content. J Pharm Technol Drug Res. 2015; 4:1.

http://dx.doi.org/10.7243/2050-120X-4-1.

16. Woisky RG, Salatino A. Analysis of propolis: some parameters and procedures for chemical quality control. Journal of Apicultural Research, 31 Dec 1997, 37(2):99-105.

http://doi:10.1080/00218839.1998.11100961.

17. Rocha BA, Bueno PC, Vaz MM, et al. Evaluation of a Propolis Water Extract Using a Reliable RP-HPLC Methodology and In Vitro and In Vivo Efficacy and Safety Characterisation. Evid Based Complement Alternat Med. 2013;2013:670451. https://doi:10.1155/2013/670451.

18. Silveira M, Teles F, Melo E, et.al. P1574 Effects of Brazilian Green Propolis Extract (Epp-Af) on Inflammation in Hemodialysis Patients. Nephrol. Dial. Transplant. 2020, 35, gfaa142.P1574.

\section{Supplementary Files}

This is a list of supplementary files associated with this preprint. Click to download.

- SPIRIT2013ChecklistBeeCovid2.doc 